\title{
Application of BOPPPS in the Standardized Training of Resident Doctors in Surgery of Traditional Chinese Medicine
}

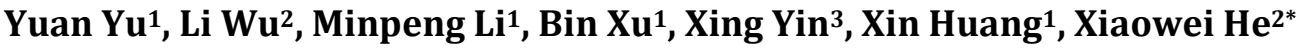 \\ ${ }^{1}$ The First Affiliated Hospital of Guangxi University of Chinese Medicine, Nanning, China \\ ${ }^{2}$ Guangxi University of Chinese Medicine, Nanning, China \\ ${ }^{3}$ Shengzhou Traditional Chinese Medicine Hospital, Shengzhou, China \\ Email: *panda_1988@126.com
}

How to cite this paper: $\mathrm{Yu}, \mathrm{Y} ., \mathrm{Wu}, \mathrm{L} ., \mathrm{Li}$, M. P., Xu, B., Yin, X., Huang, X., \& He, X. W. (2021). Application of BOPPPS in the Standardized Training of Resident Doctors in Surgery of Traditional Chinese Medicine. Creative Education, 12, 1215-1221. https://doi.org/10.4236/ce.2021.126091

Received: March 25, 2021

Accepted: May 30, 2021

Published: June 2, 2021

Copyright $\odot 2021$ by author(s) and Scientific Research Publishing Inc. This work is licensed under the Creative Commons Attribution International License (CC BY 4.0).

http://creativecommons.org/licenses/by/4.0/

(c) (i) Open Access

\begin{abstract}
Objective: Standardizing residency training for resident doctors is an important part of continuing medical education. China began to carry out standardizing residency training for resident doctors, which has made a good contribution to the development of medical industry since 1980s. BOPPS is a new teaching mode, which can bring better teaching quality and teaching effect to the standardizing residency of the surgical Traditional Chinese Medicine postgraduate students. This study observes BOPPPS teaching modes in the surgery of Traditional Chinese Medicine graduate student of resident standardization training of clinical teaching effect. Methods: Thirty students who participated in the standardized training of resident doctors for postgraduates in TCM surgery were randomly selected and divided into two groups: the teaching group and the control group, 15 students in each group, for a half-year TCM surgery technical training. The teaching reorganization adopted BOPPS model, while the control group adopted traditional teaching methods. After the completion of rotation learning, a comprehensive assessment will be made in the form of theoretical knowledge examination, practical skill operation assessment and questionnaire survey. Results: The two groups were better than the control group $(P<0.05)$ in terms of theoretical knowledge test scores of TCM surgery $(P<0.05)$, clinical practice skill test scores and questionnaire results. Conclusion: The BOPPPS teaching model can better improve the ability of resident doctors to master professional knowledge and skills in the standardized training of postgraduate students in TCM surgery, and provide a better education model for the development of standardized training of postgraduate students in TCM surgery.
\end{abstract}




\section{Keywords}

BOPPPS Teaching Methods, Surgery of Traditional Chinese Medicine, Normalized Training, Postgraduates, Education

\section{Introduction}

Standardizing residency training will help to improve the quality of the overall medical workforce. It will allow the students without secondary discipline training who otherwise will go directly to clinical practice to receive the training in clinical settings (Hu, Qi, Weng, \& Zhang, 2018). To combine the standardized residency training and postgraduate education is the result of advancing of the modern medical technologies and improvement of healthcare systems, and also it is the update to the concept of medicine education (Zhang, Wang, Wang, Yan, Fang, Dong, \& Zhao et al., 2016). Surgical Tradition Chinese Medicine is a profession that focuses on both theory and practice. How to improve the theoretical knowledge and practice proficiency of the students in 3 years of study is a difficult subject. Current training model for postgraduates in surgical Traditional Chinese Medicine relies more on the traditional classroom lectures. The effects on improving the students' theory and practice level are relatively limited ( $\mathrm{Li}$, Zhao, Gong, \& Xu, 2020). So to reform the traditional model and develop new training model is a pressing task. BOPPPS is a new training model. BOPPPS follows Bridge-in, Learning Objective, Pre-Assessment, Participatory Learning, Post Assessment and Summary 6 steps to construct a student-centered training model and develop a complete teaching method (Sun, Zhang, Deng, \& Li, 2017). This type of Interactive Instruction and Learning Model is popular in recent years in the clinical medicine education institutions and achieved positive results (Wei, Geng, \& Liu, 2019). BOPPS is a Student-Centered teaching method, which usually sets up a case for students to discuss in groups, so that students can learn together in mutual communication. Teachers mainly play a guiding role in guiding students to actively solve problems (Chen, Chen, Ke, Zhang, Zhou, \& $\mathrm{Wu}, 2020)$. BOPPPS can effectively use case discussion, which is the deficiency of traditional teaching method in the standardizing residency of the surgical TCM postgraduate students, to cultivate students' autonomous learning ability (Guo, Ren, \& Zhang, 2020). So the application of BOPPPS could help to improve the quality and effectiveness of the standardized postgraduate training of the surgical Tradition Chinese Medicine.

\section{Methodology}

\subsection{Study Subject}

Total 30 students are selected from postgraduate training program, randomly divided them into two groups, 15 students each. One group follows the new 
training model and the other as the control group. The two groups have the similar education background, both age and sex difference has no statistical significance $(P<0.05)$.

\subsection{Teaching Method}

Experimental group of students follows BOPPPS teaching method, students are introduced to the course by instructor before each lecture. Instructor will present teaching objectives clearly and conduct pre-course assessment on students. After completed the course, another assessment and review will be conducted. Comparison group follows traditional teaching method.

\subsection{Result Review}

Using two different types of teaching methods on two groups but both groups will take the same theory and practice exams. The theory exam will be conducted in closed book manner. Practice exam will be conducted with clinical operations. After the exams, the students will be given survey questionnaire to grade learning satisfaction and collaboration. And teacher will grade the students on the ability of self-study, capability of conducting research.

\subsection{Statistical Analysis}

SPSS24.0 was adopted for statistical analysis. Quantitative results are expressed as Average \pm Standard deviation $(\bar{x} \pm s)$. Rank sum test for two independent samples was adopted for the comparison between the two groups.

\section{Results}

The survey distributed 30 questionnaires, received 30 responses: 15 students in experimental group and 15 students in control group. The result shows, there is no statistically significant difference between the two groups on the surgical Chinese Tradition Medicine theory exam results $(P>0.05)$ (showing in Table 1). Students in experimental group achieved better grades than the students in control group on the clinical practice skills exam $(P<0.05)$ (showing in Table 2). Students' satisfaction rating of teaching and collaboration in experimental group is higher than students' in control group $(P<0.05)$ (showing in Table 3 , Table 4). Students' ability of self-study and capability of conducting research in experimental group is higher than students' in control group $(P<0.05)$ (showing in Table 5, Table 6).

Table 1. Theory exam (Points, $\bar{x} \pm s$ ).

\begin{tabular}{ccccc}
\hline Group & Sample & Average & $Z$ Value & $P$ Value \\
\hline Experimental & 15 & $85.47 \pm 5.05$ & & \\
Control & 15 & $87.53 \pm 5.14$ & -0.87 & 0.38 \\
\hline
\end{tabular}


Table 2. Practice exam (Points, $\bar{x} \pm s$ ).

\begin{tabular}{ccccc}
\hline Group & Sample & Average & $Z$ Value & $P$ Value \\
\hline Experimental & 15 & $86.13 \pm 5.66$ & -0.32 & 0.00 \\
Control & 15 & $77.73 \pm 6.62$ & & \\
\hline
\end{tabular}

Table 3. Satisfaction (Cases, \%).

\begin{tabular}{cccccccc}
\hline Group & Sample & Satisfied & Average & Unsatisfied & Percentage & $Z$ & $P$ \\
\hline Experimental & 15 & 13 & 1 & 1 & $86.67 \%$ & & \\
Control & 15 & 6 & 7 & 2 & $40.00 \%$ & & 0.02 \\
\hline
\end{tabular}

Table 4. Collaboration (Cases, \%).

\begin{tabular}{cccccccc}
\hline Group & Sample & Good & Average & Poor & Percentage & $Z$ & $P$ \\
\hline Experimental & 15 & 11 & 4 & 0 & $73.33 \%$ & & \\
Control & 15 & 4 & 5 & 6 & $26.67 \%$ & & 0.00 \\
\hline
\end{tabular}

Table 5. Self-study (Points, $\bar{x} \pm s$ ).

\begin{tabular}{ccccc}
\hline Group & Sample & Average Points & $Z$ Value & $P$ Value \\
\hline Experimental & 15 & $91.07 \pm 3.75$ & -2.65 & 0.01 \\
Control & 15 & $86.07 \pm 5.01$ & & \\
\hline
\end{tabular}

Table 6. Research thinking (Points, $\bar{x} \pm s$ ).

\begin{tabular}{ccccc}
\hline Group & Sample & Average Points & $Z$ Value & $P$ Value \\
\hline Experimental & 15 & $91.67 \pm 1.63$ & -4.05 & 0.00 \\
Control & 15 & $85.73 \pm 3.28$ & & \\
\hline
\end{tabular}

\section{Discussion}

The purpose of BOPPPS teaching model is to improve students' ability of self-study. Let students learn from the interaction with the teacher and the involvement in the process of the teaching. The teacher will guide the students on how to learn by themselves and how to attack the problem and proactively search for the solution (Gong \& Wang, 2018; Liang, 2020). Combining BOPPPS and standardized residency training will divide the training of surgical TCM into 6 phases. At the same time, conduct the pre-assessment, interactive learning, effectiveness assessment, review and survey along the process of training.

$\mathrm{B}$ (ridge-in). Present a real life clinical case, increase the interest in learning through the understanding of the details of the case. Further promote students to focus on the key knowledge points that need to be mastered and come up with the objectives of the learning.

$\mathrm{O}$ (bjective). Listing clearly the basic theories of surgical TCM that the students have to master as well as the principles and required proficiency of the skills in the treatments for the common diseases, frequently-occurring diseases in the 
postgraduate residency standardized training process.

$\mathrm{P}$ (re-assessment). Analyze the learning progress of the students and determine if any adjustment is required to the course plan and schedule.

$\mathrm{P}$ (articipatory learning). Besides following the teacher to the daily clinical practice, students are allowed to ask questions anytime, study references, treatment guidelines and participate in case discussion. Teacher will answer the questions from students first and summarize the knowledge points from the questions. Then the teacher will focus on the analysis of the key points of the knowledge. At last the students will practice the standardized skills and operations.

$\mathrm{P}$ (ost-accessment). Assess if the postgraduate students have demonstrated the capability required by the training objectives. After the standardized training of surgical TCM, an assessment will be conducted to understand students' level of theoretical knowledge and proficiency of clinical practice skills. At the same time, a survey will be conducted to learn about the feedback on the teaching from the program participants, also the teacher will appraise the learning attitude of the students.

S(ummary). The teacher will summarize the contents of the training and feedbacks on the teaching from the students. Teacher and students will be joining a seminar to discuss how to improve the course in both contents and the way of teaching and bring up the issues discovered in the teaching as well as how to keep up the strength.

This study showed that both groups show similar results in theory exam. That means both ways of teaching are able to help students to master theoretical knowledge well, but BOPPPS works much better on the practical skills test and the feedbacks from the students and teacher after the training. That shows BOPPPS is able to promote interest of learning, increase the ability of learning, enhance collaboration in the process of learning and encourage thinking in the way that clinical practice and research work require.

The clinical medicine education is attracting more attention in China. And the postgraduate education in clinical medicine and standardized residency training is the key area that needs more focus and further development. Standardized training in postgraduate education is the key part of the clinical education of TCM. How to improve the capability of clinical practice and research of postgraduate students in surgical TCM? China need to make great effort to develop TCM and construct an effective training model for postgraduate education of surgical TCM and improve the quality, improve the capability on self-study, collaboration, clinical practice and research thinking.

\section{Conclusion}

In conclusion, this study used two different teaching modes to test the performance of the surgical TCM postgraduate students. After the teaching, the questionnaire was used to investigate the teachers on learning satisfaction, collaboration, and the students on the ability of self-study, capability of conducting re- 
search. This study proves that the BOPPPS is more suitable for the training of the surgical TCM postgraduate students compared with the traditional teaching method. Teachers apply BOPPPS to make teaching more flexible, enhance teamwork and students management and provide scientific theory and practical solution to the standardized training on the surgical TCM postgraduate education.

\section{Funding}

Project supported by the Guangxi Zhuang Autonomous Region-level Degree and Postgraduate Education Reform Project of Guangxi University of Chinese Medicine in 2020, China (Grant No. JGY2020106); Higher Education Undergraduate Teaching Reform Project of Guangxi Zhuang Autonomous Region, China (Grant No. 2020JGB227); Education Teaching Reform and Research Project of Guangxi University of Chinese Medicine in 2018, China (Grant No. 2018C15).

\section{Conflicts of Interest}

The authors declare no conflicts of interest regarding the publication of this paper.

\section{References}

Chen, Y., Chen, W., Ke, C. X., Zhang, Z. H., Zhou, Z. M., \& Wu, Y. Q. (2020). Application of BOPPPS Teaching Model in Postgraduate Course Teaching. Education Teaching Forum, 214-216.

Gong, Z. M., \& Wang, H. X. (2018). Structure and Model Construction of the Intelligence Classroom Resources Environment. China Medical Education Technology, 32, 134-137.

Guo, Y. S., Ren, X. Q., \& Zhang, Y. K. (2020). Thoughts and Suggestions on Improving the Quality of Standardized Training of Resident Physicians for Professional Postgraduate Students under the Background of the Coordination of Medical Education and Education. Chinese Medicine Modern Distance Education of China, 18, 23-25.

Hu, X. Z., Qi, Y. H., Weng, J., \& Zhang, S. (2018). The Application of Tutorial System Teaching Mode in Standardized Training of Emergency Resident Doctors. China Higher Medical Education, 10-11.

Li, R. L., Zhao, J. M., Gong, J. Y., \& Xu, X. H. (2020). Problems and Countermeasures to Deepen the Reform of "Dual-Track Integration" Talents Training Mode for Master of Traditional Chinese Medicine under the Background of Medical Education Cooperation. Lishizhen Medicine and Materia Medica Research, 31, 2756-2757.

Liang, Z. (2020). Teaching Design and Practice of Intensive Reading Course Based on BOPPPS. Journal of Language Teaching and Research, 11, 503-508. https://doi.org/10.17507/jltr.1103.21

Sun, X., Zhang, B. B., Deng, Y. Y., \& Li, J. (2017). Exploration on Teaching Reform of Fundamental Theory of Traditional Chinese Medicine Based on BOPPPS. Chinese Medicine Modern Distance Education of China, 15, 14-16.

Wei, S. H., Geng, J. B., \& Liu, X. W. (2019). Discussion on the Connotation and Application Method of BOPPPS Teaching Model. Education and Teaching Forum, 11, 198-199.

Zhang, W., Wang, X. P., Wang, H., Yan, X. L., Fang, Y., Dong, Y., Zhao, F. et al. (2016). 
Investigation on Clinical Research Ability Cultivation Connecting Clinical Degree Postgraduate Education with Standardized Training of Resident Physicians. China Higher Medical Education, 126-128. 